\title{
FORMULAÇÃO DE BARRAS MISTAS DE FRUTAS AMAZÔNICAS
}

Marília Temporim Furtado ${ }^{1}$, Maria Luzenira de Souza ${ }^{2}$, Jocirene dos Santos da Silva ${ }^{3}$

${ }^{1}$ Eng. Agr., Mestre em Agronomia, Universidade Federal do Acre (UFAC), Rio

Branco, AC, Brasil. Email:matemporim@gmail.com

${ }^{2}$ Professora Titular do Departamento de Ciências Biológicas e da Natureza, Universidade Federal do Acre, Brasil

${ }^{3}$ Eng. Agr., Mestre em Agronomia, Universidade Federal do Acre (UFAC), Brasil.

Recebido em: 06/04/2018 - Aprovado em: 10/06/2018 - Publicado em: 20/06/2018 DOI: 10.18677/EnciBio_2018A52

\begin{abstract}
RESUMO
Frutas regionais da Amazônia podem ser utilizadas para produção de alimentos saudáveis. Neste sentido, o objetivo deste trabalho foi elaborar formulações de barras mistas de frutas contendo banana comprida, subgrupo Terra (AAB), castanha-dobrasil e cupuaçu, e caracterizar os parâmetros físico-químicos. Foram desenvolvidas formulações diferentes de barras mistas de frutas, estabelecendo-se limites mínimos de $65 \%$ de banana, $10 \%$ de castanha-do-brasil e $5 \%$ de cupuaçu. Para a otimização do processo utilizou-se o delineamento estatístico simplex lattice com 10 formulações da mistura, obtendo-se as barras mistas de frutas desidratadas. As amostras foram submetidas às análises físico-químicas de atividade de água, $\mathrm{pH}$, sólidos solúveis, acidez titulável, ácido ascórbico, e composição centesimal de proteína, cinzas, lipídeos, umidade, fibras e carboidrato, e também valor calórico total. Os resultados foram avaliados pela metodologia de superfície de resposta em curva de contorno triangular, utilizando-se o programa Statgraphics (versão trial). Os modelos obtidos para as respostas experimentais foram avaliados em termos de valores de $\mathrm{F}$ ao nível de $5 \%$ de probabilidade. As formulações desenvolvidas são viáveis para produção de barras alimentícias; a otimização das formulações contendo $65 \%$ de banana, $10 \%$ de castanha-do-brasil e $25 \%$ de cupuaçu apresentam os valores ótimos de lipídeos, valor calórico total e umidade. A formulação que contém $65 \%$ de banana, $30 \%$ de castanha-do-brasil e $5 \%$ de cupuaçu apresenta valores ótimos de proteínas, fibras e carboidratos. Desse modo apresentam características físicoquímicas adequadas e consideradas fontes de proteínas, lipídios e energia, podendo ser uma alternativa ao aproveitamento destas matérias primas para agregar valor aos produtos regionais.
\end{abstract}

PALAVRAS-CHAVE: barra de frutas, desidratação, formulações.

\section{FORMULATION OF THE FRUIT BARS}

\section{ABSTRACT}

Regional Amazonian fruits can be used for production of healthy food. In this sense, the objective of this study was to develop formulations of mixed fruit bars containing banana Long, land subgroup (AAB), chestnut-Brazil and cupuaçu, and characterize the physical and chemical parameters. Different formulations of mixed fruit bars have been developed, by establishing minimum limits of $65 \%$ of banana, $10 \%$ of Brazil ENCICLOPÉDIA BIOSFERA, Centro Científico Conhecer - Goiânia, v.15 n.27; p. $48 \quad 2018$ 
Chestnuts and $5 \%$ cupuaçu. To optimize the process used the simplex lattice statistical design mixing the formulations with 10 to give the mixed dried fruit bars. The samples were subjected to physical and chemical analysis of water activity, $\mathrm{pH}$, soluble solids, titratable acidity, ascorbic acid, and chemical composition of protein, ash, lipids, moisture, fiber and carbohydrates, and also total caloric value. The results were evaluated by response surface methodology in triangular contour curve, using the Statgraphics program (trial version). The models for experimental responses obtained were evaluated in terms of $\mathrm{F}$ values at $5 \%$ probability. The formulations are developed to produce viable food bars; the optimization of formulations containing $65 \%$ of banana, $10 \%$ of Chestnuts-Brazil and $25 \%$ of cupuaçu have the optimal values of lipids, total caloric value and moisture. The formulation containing $65 \%$ banana, $30 \%$ brazil nut and $5 \%$ cupuaçu has optimum values of proteins, fibers and carbohydrates. In this way they present adequate physicochemical characteristics and considered sources of proteins, lipids and energy, being able to be an alternative to the use of these raw materials to add value to regional products.

KEYWORDS: fruit bars, dehydration, formulations.

\section{INTRODUÇÃO}

A região Amazônica possui diversos tipos de frutas tropicais nativas ricas em vitaminas com aromas e sabores diversificados e recursos florestais não madeireiros com grande potencial de aproveitamento industrial e econômico (MESQUITA et al., 2014). Destas destacam-se o cupuaçu (Theobroma grandiflorum Schum) e a castanha-do-brasil (Bertholletia excelsa, H. B. K.). Ressalta-se ainda que na região Norte e Nordeste do Brasil tem-se o cultivo e o consumo da banana do tipo Terra (LINS et al., 2013).

A fruticultura do Brasil apresenta grande produção, porém o desperdício de frutas ainda é considerável, principalmente devido à alta perecibilidade dos frutos. De acordo com Parfitt et al. (2010) e Manzocco et al. (2016) as perdas de alimentos ocorrem, nas etapas de produção, pós-colheita e processamento na cadeia de abastecimento alimentar. No Brasil e América Latina as perdas e desperdícios na produção de frutas ocorrem principalmente nas etapas de manuseio e armazenamento (SABIO et al., 2015).

A elaboração de um produto objetivando o aproveitamento de matérias primas, comumente encontradas na região Norte do país, apresenta-se como alternativa para evitar o desperdício e perdas pós-colheita, estimulando o consumo de alimentos importantes, do ponto de vista nutricional e funcional, para a manutenção da saúde e segurança alimentar da população. Neste segmento, as barras de frutas concentradas e desidratadas apresentam-se como um produto nutritivo e energético para 0 consumo em todas as faixas etárias, com vida útil prolongada quando comparada com as frutas in natura, além de geração de renda para a região de produção (SUNWATERHOUSE et al., 2010; PARN et al., 2015).

As frutas além da importância na complementação alimentar, fornecem também subprodutos. Dentre estes as barras mistas de frutas compostas por duas ou mais combinações de matérias primas que podem ser incorporadas ao cotidiano alimentar da população brasileira como um alimento prático e saudável (CARVALHO et al., 2013). Isso porque, de acordo com Barros e Batista (2017) rotinas intensas de trabalho e falta de tempo para uma adequada alimentação estão entre as principais causas para as mudanças de hábitos que levaram ao aumento do consumo de produtos industrializados. 
A obtenção de produtos alimentícios de estimado valor nutritivo, com características de alimento funcional e de baixo custo tem sido foco de estudos nos últimos tempos. Martins et al. (2013) relatam que os consumidores estão mais conscientes e preocupados com o estilo de vida, o que aumentou a demanda por alimentos que promovem a saúde e bem-estar, tais como produtos funcionais. $O$ mercado de barras de cereais e frutas está em crescimento constante, e isso leva a indústria a diversificar a variedade de sabores (LAYMAN, 2014).

Neste contexto, as barras alimentícias obtidas da mistura ou combinação de três ou mais produtos higienicamente preparados, com específicos valores nutritivos e de sabor, tornam-se alternativas de consumo de alimentos benéficos à saúde. $O$ desenvolvimento de novos produtos com ingredientes saudáveis e funcionais, além de saborosos são bastante consideráveis nos dias atuais, uma vez que o consumidor tende a buscar a ingestão de alimentos mais saudáveis e com teores de açúcar, gorduras e sal restritos (BRIZOLA; BAMPI, 2014; OLIVEIRA et al., 2015).

A relação da nutrição e saúde é um tema de interesse da população (NEGRI et al., 2016). O crescente consumo de frutas em busca de uma alimentação mais saudável, juntamente com a preocupação da redução de dietas calóricas, faz com que o valor alimentício de frutas seja importante, principalmente, como alternativa de suplementação alimentar para a população. Neste sentido, as frutas têm conquistado novos espaços dentro do mercado interno e externo. Admitindo atributos sensoriais e benefícios à saúde, é pertinente reportar a necessidade em pesquisar novos ingredientes alimentícios (ROBERTO et al., 2015).

Considerando-se que o consumo de barras alimentícias vem ganhando espaço no mercado, principalmente por ser um alimento saudável e prático para o consumo, e visando o aproveitamento de frutas da região amazônica este trabalho teve como objetivos: a elaboração e otimização de formulações de barras alimentícias a partir da mistura de banana comprida, castanha-do-brasil e cupuaçu, bem como caracterizá-las quanto aos seus aspectos quantitativos.

\section{MATERIAL E MÉTODOS}

O experimento foi conduzido na Unidade de Tecnologia de Alimentos (UTAL) da Universidade Federal do Acre. As matérias primas utilizadas nas formulações (banana comprida, subgrupo Terra (AAB), castanha-do-brasil e cupuaçu) foram adquiridas no comércio do município de Rio Branco - Acre.

Os frutos de banana e cupuaçu foram obtidos no estádio de maturação fisiológica completamente maduros, lavados em água corrente e higienizados, por imersão, com água clorada (150 ppm de cloro ativo/15min). A seguir, as bananas foram descascadas e cortadas transversalmente em $0,5 \mathrm{~cm}$ de espessura com uso de faca de aço inoxidável. Os cupuaçus foram despolpados manualmente, utilizandose tesoura de aço inox devidamente sanitizada. As amêndoas de castanha-do-brasil foram adquiridas já desidratadas com umidade média de 2,29\%. Para a desidratação da polpa do cupuaçu foi utilizada $300 \mathrm{~g}$ de polpa, homogeneizou-se por um minuto em multiprocessador e distribuiu-se uniformemente sobre filme de PVC em camada de um $\mathrm{cm}$ de espessura.

Testes preliminares foram realizados para determinar o tempo de desidratação da banana e do cupuaçu utilizando-se estufa de secagem com circulação e renovação de ar a temperatura média de $59{ }^{\circ} \mathrm{C}$ (variação de 58 a $60{ }^{\circ} \mathrm{C}$ ). Foram determinados os tempos de desidratações de oito horas para a banana comprida (subgrupo Terra) e 17 horas para a polpa de cupuaçu. 
Foram desenvolvidas 10 formulações diferentes de barras mistas de frutas, cujas proporções dos ingredientes utilizados foram obtidas, após uma sequência de testes preliminares, e a definição das proporções finais conforme Tabela 1. Adotou-se as restrições de limite mínimo de $65 \%$ de banana comprida, 10\% de castanha-do-brasil e $5 \%$ para cupuaçu, gerando as 10 formulações citadas. O delineamento experimental empregado na elaboração das formulações foi o simplex lattice.

TABELA 1 - Delineamento simplex lattice com 10 tratamentos para as formulações das misturas de barras de frutas (45 g) contendo banana, castanha-do-brasil e cupuaçu.

\begin{tabular}{cccccrr}
\hline \multicolumn{7}{c}{ Proporções das matérias primas } \\
\hline \multirow{2}{*}{ Tratamento } & $\mathbf{R}(\mathbf{g})$ & $\mathbf{N}(\%)$ & $\mathbf{R}(\mathbf{g})$ & $\mathbf{N}(\%)$ & $\mathbf{R}(\mathbf{g})$ & $\mathbf{N}(\%)$ \\
F1 & 38,25 & 85,00 & 4,50 & 10,00 & 2,25 & 5,00 \\
F2 & 29,25 & 65,00 & 13,50 & 30,00 & 2,25 & 5,00 \\
F3 & 29,25 & 65,00 & 4,50 & 10,00 & 11,25 & 25,00 \\
F4 & 33,75 & 75,00 & 9,00 & 20,00 & 2,25 & 5,00 \\
F5 & 33,75 & 75,00 & 4,50 & 10,00 & 6,75 & 15,00 \\
F6 & 29,25 & 65,00 & 9,00 & 20,00 & 6,75 & 15,00 \\
F7 & 32,25 & 71,66 & 7,50 & 16,66 & 5,25 & 11,66 \\
F8 & 35,25 & 78,33 & 6,00 & 13,33 & 3,75 & 8,33 \\
F9 & 30,75 & 68,33 & 10,50 & 23,33 & 3,75 & 8,33 \\
F10 & 30,75 & 68,33 & 6,00 & 13,33 & 8,25 & 18,33 \\
\hline
\end{tabular}

R: Valor real (absoluto); N: Valor normalizado (relativo)

Para modelar cada tratamento (formulação), pesaram-se as matérias-primas separadamente, em balança, de acordo com a definição do delineamento experimental proposto. Posteriormente, as matérias-primas foram trituradas em multiprocessador e misturadas até formar uma massa homogênea. Cada mistura (formulação) foi comprimida em fôrmas específicas para barras alimentícias para formatação com massa de $45 \mathrm{~g}$.

Após a formatação, as barras de frutas foram desidratadas em estufa com circulação e renovação de ar com temperatura média de $59^{\circ} \mathrm{C}\left(58\right.$ a $\left.60^{\circ} \mathrm{C}\right)$ por nove horas. Esse processo consistiu em expor as barras mistas a uma corrente continua de ar quente para remover a umidade.

As barras de frutas foram embaladas em papel manteiga (embalagem primária), seguida de papel alumínio (embalagem secundária) e armazenadas em temperatura ambiente média de $25,68 \pm 0,03{ }^{\circ} \mathrm{C}$ e umidade relativa de $84,67 \pm 0,11 \%$ até $\mathrm{o}$ momento da realização das análises.

As amostras foram submetidas às análises físico-químicas de atividade de água, $\mathrm{pH}$, sólidos solúveis, acidez titulável, ácido ascórbico, e composição centesimal de proteína, cinzas, lipídeos, umidade, fibras e carboidrato, segundo a metodologia do Instituto Adolfo Lutz (2008), e também valor calórico total, calculado com base na composição de cada formulação das barras de frutas, sendo utilizados os fatores de conversão de Atwater: proteínas $4 \mathrm{kcal} \mathrm{g}^{-1}$, carboidratos $4 \mathrm{kcal} \mathrm{g}^{-1} \mathrm{e}$ lipídeos $9 \mathrm{kcal} \mathrm{g}^{-1}$, conforme Resolução - RDC ANVISA/MS $\mathrm{n}^{\circ}$ 360, de 23 de dezembro de 2003 (BRASIL, 2003).

Foi utilizada a metodologia de superfície de resposta mediante delineamento simplex lattice, aumentado para 10, que faz parte do delineamento de misturas e superfície de resposta triangular para a descrição matemática da modelagem de 
misturas. Os resultados foram submetidos à análise estatística, utilizando-se o programa Statgraphics (versão trial). Os modelos para as respostas das variáveis experimentais foram obtidos mediante análise de variância de regressões ao nível de $5 \%$ de probabilidade. A curva de contorno foi empregada para ilustrar o desempenho de cada variável físico-química avaliada em função das proporções entre os três ingredientes utilizados.

\section{RESULTADOS E DISCUSSÃO}

Os resultados das variáveis físico-químicas obtidos na otimização das 10 formulações de barras mistas de frutas estão apresentados na Tabela 2. A otimização indicou a formulação contendo $65 \%$ de banana, $10 \%$ de castanha-dobrasil e $25 \%$ de cupuaçu como a indicada para alcançar os valores ótimos para as variáveis de lipídeos, valor calórico total e umidade, conforme demonstrado na Tabela supracitada.

TABELA 2 - Valores otimizados das variáveis físico-químicas das barras mistas de frutas com diferentes proporções de banana, castanha-do-brasil e cupuaçu.

\begin{tabular}{|c|c|c|c|}
\hline \multirow[b]{2}{*}{ Variáveis físico-químicas otimizadas } & \multicolumn{3}{|c|}{ Ingredientes } \\
\hline & $\begin{array}{c}\text { Banana } \\
(65-85 \%)^{*}\end{array}$ & $\begin{array}{c}\text { Castanha-do-brasil } \\
(10-30 \%)^{*}\end{array}$ & $\begin{array}{l}\text { Cupuaçu } \\
(5-25 \%)^{*}\end{array}$ \\
\hline Proteínas $\left(6,28{\left.\mathrm{~g} 100 \mathrm{~g}^{-1}\right)}\right.$ & 65,00 & 30,00 & 5,00 \\
\hline 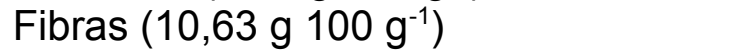 & 65,00 & 30,00 & 5,00 \\
\hline 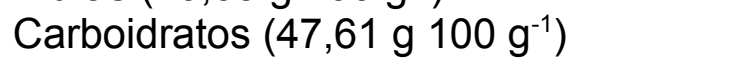 & 65,00 & 30,00 & 5,00 \\
\hline 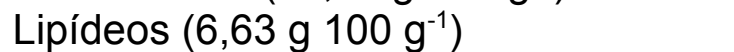 & 65,00 & 10,00 & 25,00 \\
\hline 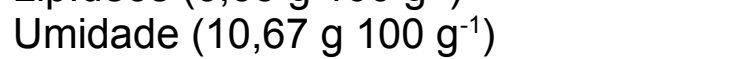 & 65,00 & 10,00 & 25,00 \\
\hline Valor calórico total $\left(318,07 \mathrm{Kcal} 100 \mathrm{~g}^{-1}\right)$ & 65,00 & 10,00 & 25,00 \\
\hline 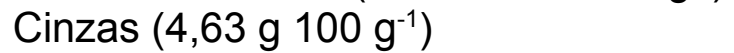 & 70,48 & 16,56 & 12,94 \\
\hline Atividade de água $(0,6)$ & 65,30 & 23,75 & 10,94 \\
\hline Sólidos solúveis $\left(60,08^{\circ} \mathrm{Brix}\right)$ & 85,00 & 10,00 & 5,00 \\
\hline Acidez titulável $(1,8 \%)$ & 81,74 & 13,13 & 5,11 \\
\hline $\mathrm{pH}(4,64)$ & 68,71 & 25,15 & 6,13 \\
\hline Ácido ascórbico $\left(157,52 \mathrm{mg} 100 \mathrm{~g}^{-1}\right)$ & 79,08 & 15,91 & 5,00 \\
\hline
\end{tabular}

$\mathrm{Na}$ Tabela 2 para as variáveis lipídeos e umidade os valores mínimos

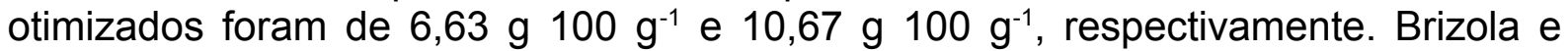

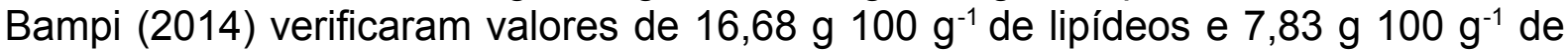
umidade para barras alimentícias adicionadas de farinha de banana verde. Já Marchese e Novello (2017) encontraram conteúdo de lipídeos de 13,65 g $100 \mathrm{~g} \mathrm{~g}^{-1} \mathrm{em}$ elaboração de barra de cereal salgada. $O$ teor de umidade deve ser considerado no desenvolvimento de barras de frutas, pois não só afeta a qualidade dos produtos (como textura, sabor e aparência) mais também a estabilidade do alimento (PARN et al., 2015).

As Figuras de 1 a 3 representam as superfícies de resposta geradas pela projeção das equações (Tabela 3 ) em um diagrama de coordenadas triangular. As equações das variáveis representam os modelos estatísticos para cada uma das análises físico-químicas estudadas. Os modelos de superfícies de respostas foram definidos com base na significância dos valores de $F$ das regressões, onde as variáveis são: $\mathrm{x}=$ proporção da banana na mistura, $\mathrm{y}=$ proporção de castanha-dobrasil e $z$ = proporção de cupuaçu. Segundo Faraoni et al. (2013), a interpretação das ENCICLOPÉDIA BIOSFERA, Centro Científico Conhecer - Goiânia, v.15 n.27; p. $52 \quad 2018$ 
propriedades da mistura e a seleção dos componentes que produzem uma região ótima da superfície investigada são facilitadas plotando a forma tridimensional da superfície, bem como pelas curvas de nível.

TABELA 3 - Equações de regressão ajustadas.

\begin{tabular}{llr}
\hline Variável & \multicolumn{1}{c}{ Equação de regressão ajustada } & $R^{2}$ \\
\hline SS & $60,09^{*} x+48,02^{*} y+35,15^{*} z-79,56^{*} x^{*} y-47,16^{*} x^{*} z+8,69^{*} y^{*} z$ & 85,97 \\
AT & $1,86^{*} x+1,10^{*} y+11,15^{*} z+0,09^{*} x^{*} y-5,24^{*} x^{*} z-3,96^{*} y^{*} z+23,63^{*} x^{*} y^{*} z$ & 97,98 \\
AA & $140,58^{*} x+61,48^{*} y+124,80^{*} z+193,67^{*} x^{*} y-289,00^{*} x^{*} z-191,38^{*} y^{*} z$ & 76,20 \\
pH & $1088,01^{*} x^{*} y^{*} z$ & 97,35 \\
Proteínas & $4,43^{*} x+5,10^{*} y+3,81^{*} z-1,38^{*} x^{*} y-0,01^{*} x^{*} z-1,66^{*} y^{*} z$ & 43,97 \\
Cinzas & $4,91^{*} x+6,28^{*} y+4,91^{*} z$ & 71,08 \\
Lipídeos & $3,81^{*} x+2,59^{*} y+3,30^{*} z-1,85^{*} x^{*} y-1,13^{*} x^{*} z+3,57^{*} y^{*} z+34,96^{*} x^{*} y^{*} z$ & 94,12 \\
Fibras & $7,81^{*} x+19,75^{*} y+6,63^{*} z$ & 72,24 \\
Carboidratos & $4,26^{*} x+10,64^{*} y+6,69^{*} z+1,43^{*} x^{*} y+5,63^{*} x^{*} z+3,73^{*} y^{*} z-53,34^{*} x^{*} y^{*} z$ & 46,23 \\
VCT & $34,97^{*} x+46,23^{*} y+66,79^{*} z$ & 23,44 \\
Umidade & $11,01^{*} x+14,06^{*} y+10,67^{*} z$ & 28,27 \\
Aw & $0,48^{*} x+0,64^{*} y+0,15^{*} z+0,33^{*} x^{*} y-0,29^{*} x^{*} z-0,03^{*} y^{*} z$ & 84,42 \\
\hline
\end{tabular}

O diagrama triangular mostrado na Figura 1, para valor calórico total esboça o valor mínimo otimizado de $318,07 \mathrm{Kcal} 100 \mathrm{~g}^{-1}$, sendo ajustado o modelo linear a $5 \%$ de probabilidade. A adição de castanha-do-brasil nas barras mistas de frutas justifica o maior valor calórico encontrado. Estes resultados são comparáveis aos encontrados por Colussi et al. (2013) que obtiveram valor calórico total de barras de cereais entre 324,11 e 421,84 Kcal $100 \mathrm{~g}^{-1}$. Já na elaboração de "snack" de farinha de tapioca, castanha-do-brasil e cupuaçu, Prazeres et al. (2017) verificaram valor calórico de 435,66 Kcal $100 \mathrm{~g}^{-1}$.

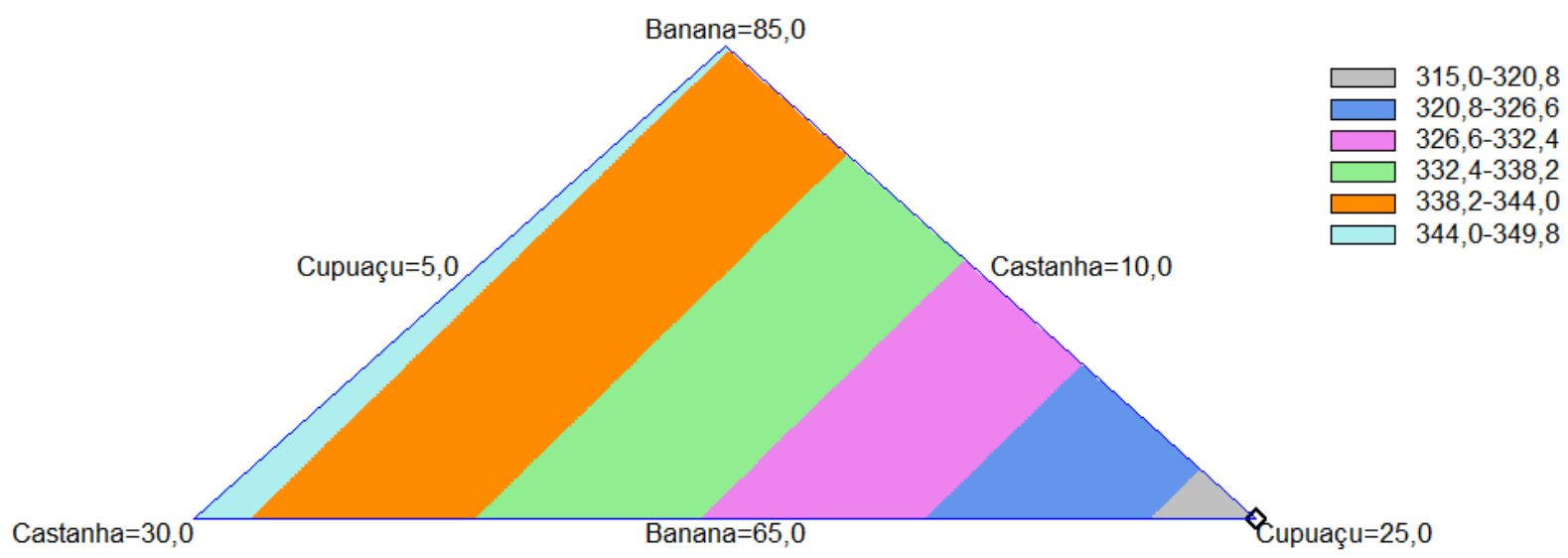

FIGURA 1 - Contorno da superfície de resposta para valor calórico total (Kcal $100 \mathrm{~g}^{-1}$ ) em barras mistas de frutas compostas por banana, castanha-do-brasil e cupuaçu. 
Aplicando a técnica de otimização (Tabela 1), a melhor formulação da mistura

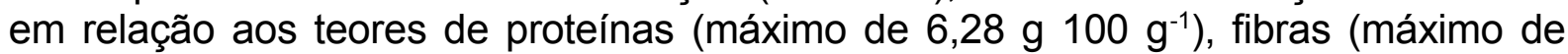
10,63 g $100 \mathrm{~g} \mathrm{~g}^{-1}$ ) e carboidratos (mínimo de 47,61 g $100 \mathrm{~g}^{-1}$ ) foi a que apresentou 65\% de banana, $30 \%$ de castanha do Brasil e $5 \%$ de cupuaçu. A região de combinação entre as três variáveis $\mathrm{X}, \mathrm{Y}$ e $\mathrm{Z}$ pode ser observada através da Figura 2 para a variável proteínas, sendo que o melhor modelo ajustado foi o linear a $1 \%$ de probabilidade.

Neste caso, os valores demonstram que se podem considerar as barras mistas de frutas amazônicas como sendo fonte de fibras, já que segundo a Portaria $n^{\circ} 27$, de 13 de janeiro de 1998, da Agência Nacional da Vigilância Sanitária (BRASIL, 1998), alimentos sólidos são considerados fonte de fibra alimentar quando

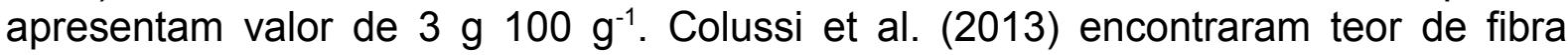
alimentar total das barras de cereais elaboradas com aveia e linhaça dourada entre

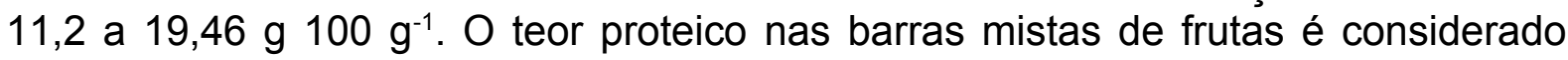
satisfatório devido a conter castanha-do-brasil, cuja composição química da sua proteína é completa (SOUZA; MENEZES, 2004), o que justifica os resultados obtidos neste trabalho. Carvalho et al. (2013) que elaboraram barras de cereais com castanha-do-gurguéia e amêndoas de sapucaia encontraram valores de proteínas

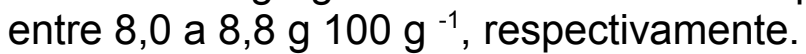

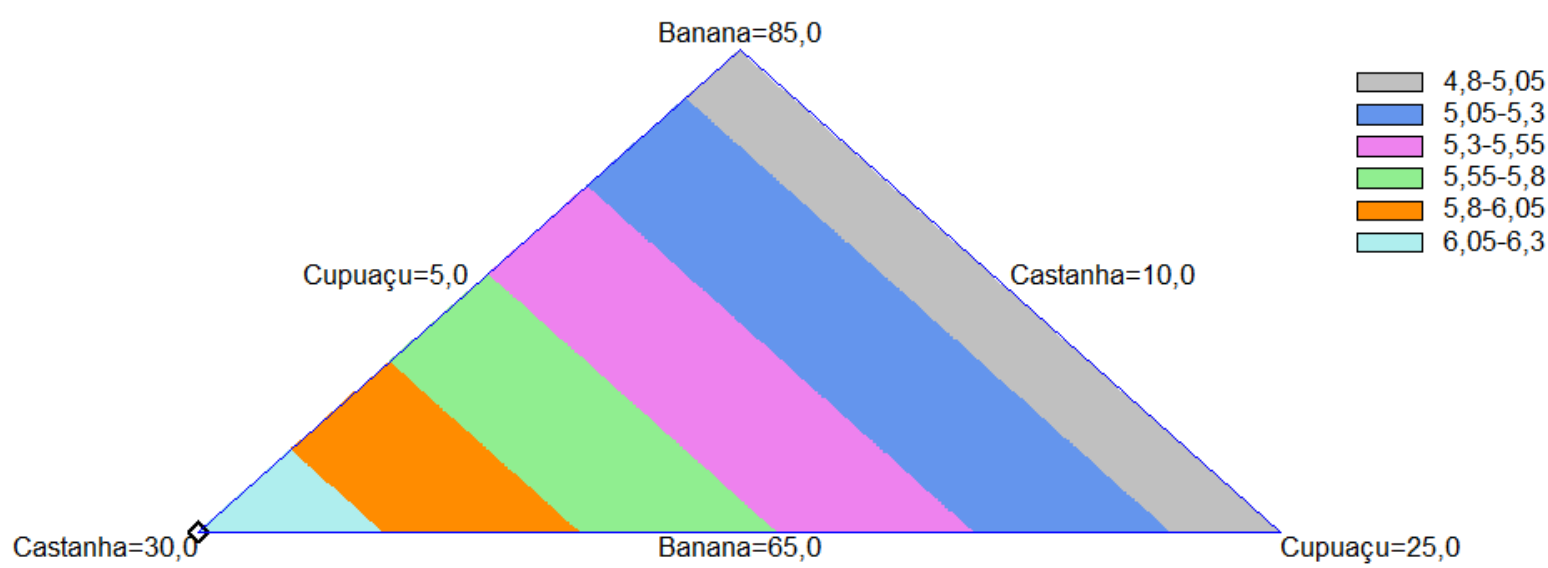

FIGURA 2 - Contorno da superfície de resposta para proteínas ( $100 \mathrm{~g}^{-1}$ ) em barras mistas de frutas compostas por banana, castanha-do-brasil e cupuaçu.

A variável otimizada atividade de água $(A w)$ apresentou valor de 0,6 como sendo o ideal para a mistura da barra mista de frutas, ajustada ao modelo quadrático $(p<0,01)$, sendo representada a região otimizada pela Figura 3. A formulação otimizada apresentou valores de $65,30 \%$ para banana, $23,75 \%$ de castanha-dobrasil e 10,94\% de cupuaçu. Na avaliação de barra de cereais com aveia e linhaça dourada, Colussi et al. (2013) encontraram valor de atividade de água dos tratamentos entre 0,56 a 0,60 . As barras alimentícias, de um modo geral, são elaboradas para manter os valores intermediários de Aw entre 0,4 e 0,6 (LOBATO et al. 2012). 


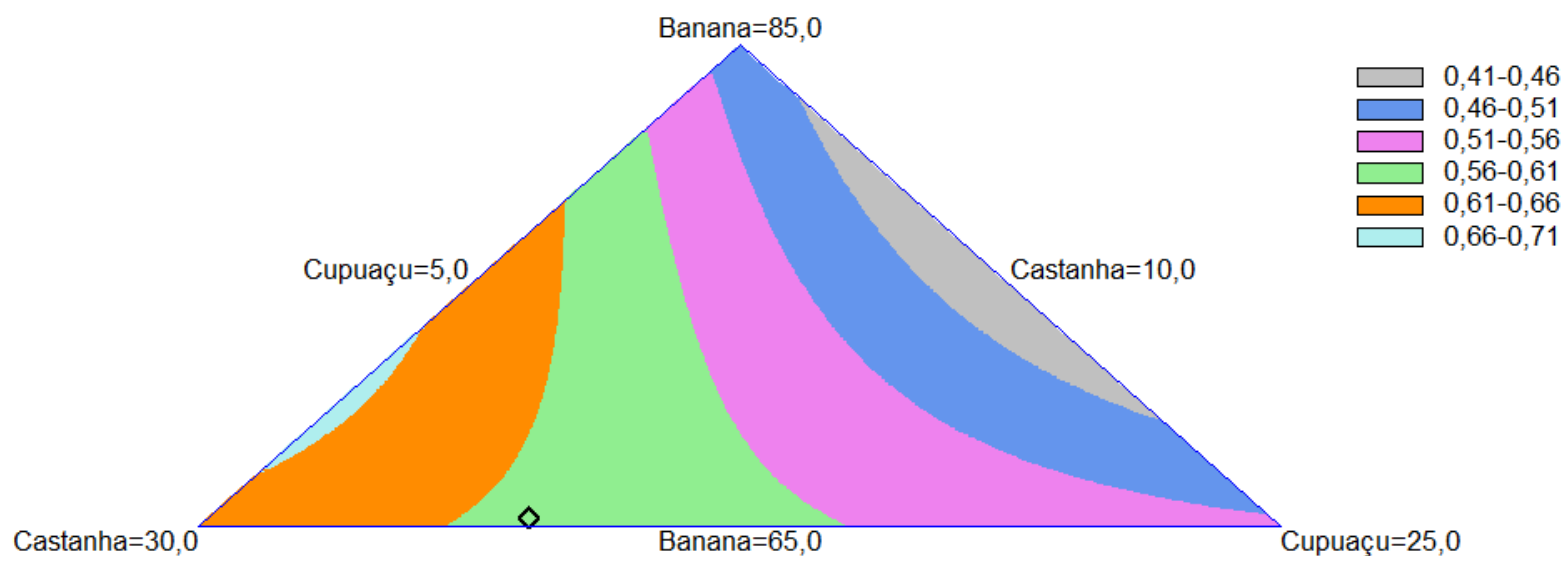

FIGURA 3 - Contorno da superfície de resposta para atividade de água (Aw) em barras mistas de frutas compostas por banana, castanha-do-brasil e cupuaçu.

Foram definidas na metodologia de otimização como sendo a ideal para a variável ácido ascórbico, as proporções de $79,08 \%$ de banana, $15,91 \%$ de castanhado-brasil e $5 \%$ de cupuaçu, tendo o seu valor otimizado em $157,52 \mathrm{mg} 100 \mathrm{~g}^{-1}$. Para o $\mathrm{pH}$, o valor ótimo encontrado foi de 4,64 . As proporções de $68,71 \%$ de banana, $25,15 \%$ de castanha do Brasil e $6,13 \%$ de cupuaçu (Tabela 1) foram definidas na metodologia de otimização como sendo a ideal para esta variável. Peuckert et al. (2010) que caracterizaram barras de cereais adicionadas de proteína texturizada de soja e camu-camu e obtiveram $14,3 \mathrm{mg} 100 \mathrm{~g}^{-1} \mathrm{em}$ teor de ácido ascórbico.

Com relação aos sólidos solúveis ('Brix), observou-se que a formulação com $85 \%$ de banana, $10 \%$ de castanha-do-brasil e $5 \%$ de cupuaçu apresentou-se sendo as proporções ideais encontradas na otimização para esta variável, ficando o valor máximo otimizado de $60,08^{\circ}$ Brix. Para o teor de acidez titulável (\%), verificou-se que o valor otimizado apresentou $1,8 \%$ de ácido cítrico mais málico, principais ácidos encontrados nos ingredientes utilizados na mistura de banana e cupuaçu. No processo de otimização as proporções definidas para esta variável mostram que a mistura que contém $81,74 \%$ de banana, $13,13 \%$ de castanha-do-brasil e $5,11 \%$ de cupuaçu foi a melhor combinação.

A formulação da mistura definida para alcançar a otimização para cinzas, contém $70,48 \%$ de banana, $16,56 \%$ de castanha-do-brasil e $12,94 \%$ de cupuaçu, sendo o

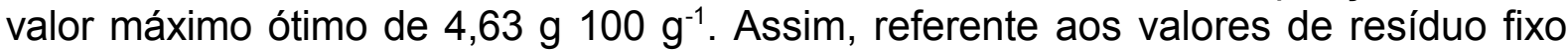
mineral obtidos nesse estudo, os teores variam quando comparados aos encontrados por Marchese e Novello (2017) de 5,09 g $100 \mathrm{~g}^{-1}$ e os valores obtidos por Roberto et al. (2015) de 1,13 a 1,45 g $100 \mathrm{~g}^{-1}$, ambos avaliando barras alimentícias com diferentes ingredientes. Deve ser levado em consideração, que o teor dos nutrientes pode variar consideravelmente de acordo com as características dos diversos ingredientes que compõe a formulação da barra alimentícia (MARCHESE; NOVELLO, 2017).

\section{CONCLUSÕES}

- As formulações desenvolvidas neste estudo são viáveis para produção de barras mistas de frutas, contendo banana comprida, castanha-do-brasil e cupuaçu. 
- As barras mistas de frutas otimizadas apresentam características físicoquímicas adequadas e consideradas fontes de proteínas, lipídios, energia;

- A produção das barras mistas de frutas é uma alternativa ao aproveitamento de frutas, onde as matérias primas são disponíveis e facilmente encontradas, o que agrega valor aos produtos regionais.

\section{AGRADECIMENTO}

A UFAC, CAPES e Fundo de Desenvolvimento de Ciência e Tecnologia do estado do Acre, através da Fundação de Tecnologia do Estado do Acre (FUNTAC).

\section{REFERÊNCIAS}

BARROS, L. de O.; BATISTA, J. S. Análise da rotulagem nutricional de barras de cereais light comercializadas em Fortaleza, Ceará. Revista de Nutrição e Vigilância em Saúde, Fortaleza, v. 3, n.3, p. 137-144, nov./fev. 2017. Disponível em: < http://www.revistanutrivisa.com.br/wp-content/uploads/2017/10/nutrivisa-vol-3num-3-f.pdf>.

BRASIL. Portaria ANVISAMMS n. 27, de 13 de janeiro de 1998. Regulamento técnico referente a informação nutricional complementar. Diário Oficial da União, Brasília, DF, 13 jan. 1998. Disponível em: <http://e-legis.bvs.br/leisref/ public/ showAct.php?id=97>.

BRASIL. Resolução RDC ANVISA/MS $n^{\circ}$ 360, de 23 de dezembro de 2003. Regulamento técnico sobre rotulagem nutricional de alimentos embalados. Diário Oficial da União, DF, 26 dez. 2003.

BRIZOLA, R.; BAMPI, G. R. Desenvolvimento de barras alimentícias com adição de farinha de banana verde. Unoesc \& Ciência - ACBS, Joaçaba, v. 5, n. 1, p. 63-68, jan./jun. 2014. Disponível em:< https://editora.unoesc.edu.br/index.php/acbs/article /download/2527/pdf_28 >.

CARVALHO, M. G. de; SILVA, L. M. R. da; MAIA, G. A.; SOUSA, P. H. M. de; FIGUEIREDO, E. A. T. et al. Composição química e estabilidade físico-química e microbiológica de barras de cereais com amêndoas nativas do meio-Norte do Brasil e casca de abacaxi. Revista Brasileira de Pesquisa em Alimentos, Campo Mourão, v. 4, n. 1, p.11-18, jan./jun., 2013. Disponível em: < https://periodicos.utfpr. edu.br/rebrapa/article/viewFile/3387/pdf>. doi: http://dx.doi.org/10.14685/rebrapa.v4i1 .101

COLUSSI, R.; BALDIN, F.; BIDUSKI, B.; NOELLO, C.; HARTMANN, V.; GUTKOSKI, L. C. Aceitabilidade e estabilidade físico-química de barras de cereais elaboradas à base de aveia e linhaça dourada. Brazilian journal of food technology, Campinas, v. 16, n. 4, p. 292-300, out./dez. 2013. Disponível em:< http://dx.doi.org/10. 1590/S1981-67232013005000035>.

FARAONI, A. S.; RAMOS, A. M; GUEDES, D. B.; PINTO, M. R. M. R. Propriedades reológicas de sucos mistos de manga, goiaba e acerola adicionados de fitoquímicos. Brazilian journal of food technology, Campinas, v. 16, n. 1, p. 21-28, jan./mar. 2013. Disponível em: <http://dx.doi.org/10.1590/S1981-67232013005000002>. 
INSTITUTO ADOLFO LUTZ (IAL). Métodos físico-químicos para análise de alimentos. 4.ed. São Paulo: IMESP, 2008.

LAYMAN, D. K. Eating patterns, diet quality and energy balance A perspective about applications and future directions for the food industry. Physiology \& Behavior, v. 134, p. 126-130, 2014. Disponível em: < https://doi.org/10.1016/j.physbeh.2013.12. 005>.

LINS, L. C. R. de; FANCELLI, M.; RITZINGER, C. H. S. P.; COELHO FILHO, M. A.; LEDO, C. A. da S. Torta de mamona no controle da broca-do-rizoma (Cosmopolites sordidus) em bananeira-Terra. Revista Brasileira de Fruticultura, Jaboticabal, v. 35, n. 2, p. 493-499, jun. 2013. Disponível em: < http://dx. doi.org/10.1590/S010029452013000200019>.

LOBATO, L. P.; PEREIRA, A. E. I. C.; LAZARETTI, M. M.; BARBOSA, D, S.; CARREIRA, C. M.; MANDARINO, J. M. G. M.; GROSSMANN, M. V. E. Snack bars with high soy protein and isoflavone content for use in diets to control dyslipidemia. International. Journal of Food Sciences and Nutrition, v. 63, n. 1, p. 49-58, 2012. Disponível em: < https://doi.org/10.3109/09637486.2011.596148>.

MANZOCCO, L.; ALONGI, M.; SILANI, S.; NICOLI, M. C. Technological and consumer strategies to tackle food wasting. Food Engineering Reviews, v. 8, n. 4, p. 457-467, dez. 2016. Disponível em: < https://link.springer.com/article/10.1007\%2 Fs12393-016-9149-z>.

MARCHESE, N. R.; NOVELLO, Z. Desenvolvimento e caracterização de barra de cereal salgada. Revista Brasileira de Tecnologia Agroindustrial, Ponta Grossa, v. 11, n. 1, p. 2150-2164, jan/jun. 2017. Disponível em:< http://dx.doi.org/10.3895/rbta. v11n1.3109>.

MARTINS, E. M. F.; RAMOS, A. M.; VANZELA, E. S. L.; STRINGHETA, P. C.; PINTO, C. L. O.; MARTINS, J. M. Products of vegetable origin: A new alternative for the consumption of probiotic bactéria. Food Research International, v. 51, p. 764770, 2013. Disponível em: <https://doi.org/10.1016/j.foodres.2013.01.047>.

MESQUITA, F. R.; LIMA, M. O.; ARAÚJO, J. M. de; RIBEIRO, O. A. S.; CRAVEIRO, R. L. Composição centesimal de frutos típicos da região do Vale do Juruá-Amazônia Ocidental. Enciclopédia Biosfera, Goiânia, v. 10, n. 19, p. 2849-2857, dez. 2014. Disponível em: < http://conhecer.org.br/enciclop/2014b/MULTIDISCIPLINAR/compo sicao\%20centesimal\%20de\%20frutos.pdf>.

NEGRI, T. C.; BERNI, P. R. de A.; BRAZACA, S. G. C. Valor nutricional de frutas nativas e exóticas do Brasil. Revista Biosaúde, Londrina, v. 18., n. 2, p. 82-96, 2016.

Disponível em:

http://www.uel.br/revistas/uel/index.php/biosaude/article/view /27615>.

OLIVEIRA, B. R. de; ALMEIDA, C. C. de; MEIRA, W. M.; FREITAS, M. Q. de. Análise sensorial de requeijão cremoso tradicional e "light" reduzido de sódio e gordura. Enciclopédia Biosfera, Goiânia, v. 11, n. 21, p. 152-158, jun. 2015. 
Disponível em: < http://www.conhecer.org.br/enciclop/2015b/agrarias/Analise\%20 sensorial\%20de\%20\%20requeijao.pdf>.

PARFITT, J.; BARTHEL, M.; MACNAUGHTON, S. Food waste within food supply chains: quantification and potencial for change to 2050. Philosophical Transactions of the Royal Society, v. 365, p. 3065-3081, 2010. Disponível em: < http://rstb.royal societypublishing.org/content/royptb/365/1554/3065.full.pdf>.

PARN, O. J.; BHAT, R.; YEOH, T. K.; AL-HASSAN, A. A. Development of novel fruit bars by utilizing date paste. Food Bioscience, v. 9, p. 20-27, 2015. Disponível em: < https://doi.org/10.1016/j.fbio.2014.11.002>.

PEUCKERT, Y. P.; VIERA, V. B.; HECKTHEUER, L. H. R.; MARQUES, C. T.; ROSA, C. S. da. Caracterização e aceitabilidade de barras de cereais adicionadas de proteína textura de soja e camu-camu (Myrciaria dúbia). Alimentos e Nutrição, Araraquara, v. 21, n. 1, p. 149-154, jan./mar. 2010. Disponível em:< http://servbib.fcfar.unesp.br/seer/index.php/alimentos/article/view/1400/922>.

PRAZERES, I. C. dos; DOMINGUES, A. F. N.; CAMPOS, P. R.; CARVALHO, A. V. Elaboration and characterization of snack bars made with ingredients from the Amazon. Acta Amazonica, Manaus, v. 47, n. 2, p. 103 - 110, 2017. Disponível em:< http://dx.doi.org/10.1590/1809-4392201602203>.

ROBERTO, B. S.; SILVA, L. P. da; MACAGNANI, F. T.; BIZZANI, M.; BENDER, A. B. $B$. Qualidade nutricional e aceitabilidade de barras de cereais formuladas com casca e semente de goiaba. Revista do Instituto Adolfo Lutz, São Paulo, v. 74, n. 1, p. 39-48, 2015. Disponível em:< ses.sp.bvs.br/lildbi/docsonline/get.php? id=5957>.

SABIO, R. P.; GARCIA, J. B; DUARTE, E. N.; PACHECO, A. L. A. Perdas e desperdícios na produção de alimentos. Hortifruti Brasil, Piracicaba, n. 148, p. 10, ago. 2015. Disponível em: < http://www.hfbrasil.org.br/br/revista/acessar/a-vez-doshfs-feios.aspx>.

SOUZA, M. L de; MENEZES, H. C. de. Processamentos de amêndoa e torta de castanha-do-brasil e farinha de mandioca: parâmetros de qualidade. Ciência e Tecnologia de Alimentos, Campinas, v. 24, n. 1, p. 120-128, jan./mar. 2004. Disponível em: < http://www.scielo.br/pdf/cta/v24n1/20052.pdf>.

SUN-WATERHOUSE, D.; TEOH, A.; MASSAROTTO, C.; WIBISONO, R.; WADHWA, S. Comparative analysis of fruit-based functional snack bars. Food Chemistry, v. 119, n. 4, p. 1369-1379, 2010. Disponível em< https://doi.org/10. 1016/j.foodchem.2009.09.016>. 